\title{
MECHANISM OF CHARGE TRANSFER IN THE DISCONTINUOUS METAL PHASE OF A FLUIDIZED BED ELECTRODE
}

\author{
A. A. C. M. Beenackers, W. P. M. VAN SwaAiJ and A. Welmers* \\ Laboratory for Chemical Reactions Engineering, Dept. of Chemical Engineering, \\ Twente University of Technology, P.O.B. 217, Enschede, The Netherlands
}

(Received 1 December 1976; and in revised form 20 February 1977)

\begin{abstract}
From measurements of double layer capacity, collision Irequency and contact time during collision, it is concluded that models for charge transfer in the discontinuous phase of a fluidized bed electrode that are based on ideal particulate fluidization cannot explain metal phase resistivities, experimentally observed.

Based on a literature survey it is shown that not only gas-solid but also liquid-solid fluidization is at least partially aggregative.

A preliminary model for charge transfer in the discontinuous phase, based on aggregative fluidization, is derived.
\end{abstract}

\section{NOMENCLATURE}

$n_{a}$

$N_{a}$

$r$

$\boldsymbol{R}$

$\boldsymbol{R}_{\boldsymbol{u}}$

$t_{c}$

$t_{6 a}$

$U_{m f}$

$x$ ribbon of cubic cluster

bulk concentration of electrolyte

double layer capacity per $\mathrm{m}^{2}$ particle surface

double layer capacity per particle

double layer capacity of aggrcgate

known capacity

Froude number, defined by (10)

gravity constant

current density in discontinunus phase per unit cross sectional area

net charge transfer per second per particle

effective distance between two particle (aggregate) centres in $x$-direction

effective interparticlc surface distance in $x$-direction

distance between adjacent

aggregate surfaces

number of particles per $\mathrm{m}^{3}$

number of particles per $\mathrm{m}^{2}$ cross section

number of particles pet aggregate

number of aggregates per $\mathrm{m}^{3}$ radius of particles

resistance of double layer

known resistance

contact time of a two-particle collision

life time of one particle-bridge

between two aggregates

minimum fluidisation velocity

direction of maximum potential gradient (m)

$\left(\mathrm{kmol} / \mathrm{m}^{3}\right)$

$\left(\mathrm{F} / \mathrm{m}^{2}\right)$

(F)

(F) $v_{a}$

(F) $v_{a}^{\prime}$

$\left(\mathrm{m} / \mathrm{s}^{2}\right) \quad \rho_{m}$

$\left(\mathrm{A} / \mathrm{m}^{2}\right)$

(A) $\tau_{a}$

(m) $\phi_{m}$

(m) $\phi_{s}$

$\left(\mathrm{m}^{-3}\right)$

$\left(\mathrm{m}^{-2}\right)$

$\left(\mathrm{m}^{-3}\right)$

(m)

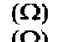

$(\Omega)$

(s)

(s)

$(\mathrm{m} / \mathrm{s})$

(m)

* Present address: 280-291 Windermere Road, London, Ontario N6G $2 J 9$. Canada.

\section{$\Delta V_{d}, \Delta V_{u}$}

$V_{d}-V_{x}$

$\epsilon_{0}$

$\rho_{s}$

change in potential of double layer and known capacity respectively, after closing $S$ (Fig. 4)

cell potential

bed height/static bed height

porosity of static bed

number of collisions per par-

tiolè per second

number of contact bridges per

aggregate per second

idem, per aggregate surface particle

effective specific resistivity of

the discontinuous phase

effective specific resistivity of

the solution phase

time constant for charge shar-

ing during a particle collision

time constant for charge shar-

ing of two aggregates during a particle bridge

potential of discontinuous

phase

solution potential

\section{INTRODUCTION}

In designing a fluidized bed electrode $(f b e)$, the effective $d c$ specific resistivity of the discontinuous phase $\left(\rho_{m}\right)$, plays a major role- Both theoretical and experimental knowledge of this parameter, however, are relatively poor. Experimental data for copper coated glass spheres of about $500 \mu \mathrm{m}$ are given in Fig. 1 .

In fact, the picture is more complicated because of local bed disturbances near the distributor, resulting in a substantially lower resistivity close to the grid[2].

In a pioneering article, Fleischmann and Oldfield[3] derived an expression based on a model of ideal particulate fluidization in which complete or parlial charge sharing occurs during elastic collisions of single particles. After substitution of estimated 


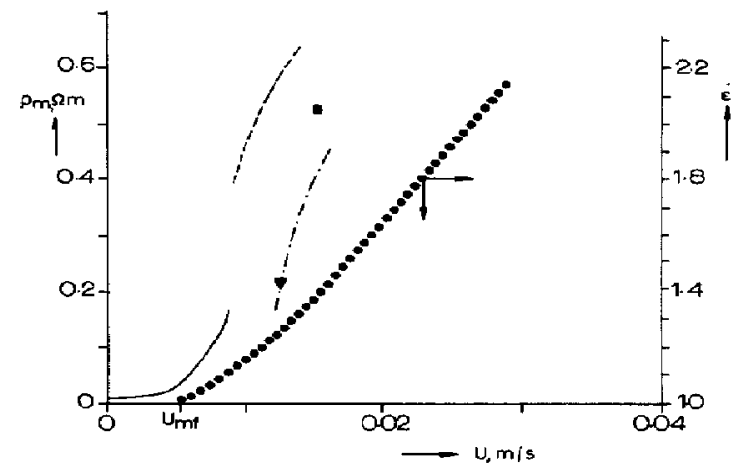

Fig. 1. Metal resistivity and bed expansion as a function of superficial liquid velocity for copper-coated glass spheres of about $500 \mu \mathrm{m} \mathrm{dia.} \mathrm{---:} \mathrm{[1],} 1 \mathrm{M} \mathrm{H}_{2} \mathrm{SO}_{4} ;-\ldots$. : [2], $1 \mathrm{M} \mathrm{H}_{2} \mathrm{SO}_{4} ;-$; our experiments, $1 \mathrm{M} \mathrm{KCl} ; \mathbf{\mathrm { K }}, \boldsymbol{\nabla}$ :

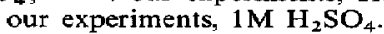

values for collision frequency $v$, double layer capacity $C_{d}$, contact time during collision $t_{s}$, and $R C$-time of a particle $\tau$, in their theoretical equation for the specific resistivity of the metal phase, they found a predicted value for $\rho_{m}$ which was higher than experimental findings[1]. For this reason we measured $v$, $C_{d}, t_{c}$ and $\tau$. The result was an even greater discrepancy hetween thenry and experiment. Thus we concluded that a model based on ideal particulate fluidization is not realistic, at least not for practically important bed expansions below $30 \%$.

Based on recent experimental evidence for the existence of aggregative fluidization, not only in gas-solid but also in liquid-solid fluid beds, we suggest a model for charge transfer based on the occurrence in the bed of particle aggregates in which the potential is uniform. The relation between the aggrega te diameter and $\rho_{m}$ can be understood qualitatively.

\section{THE SINGLE PARTICLE COLLISION MONEL, PASEN ON IDEAL PARTICULATE FLUIDIZATION}

For the case of

$$
(\Delta l) \mathrm{d} \phi_{\mathrm{s}} / \mathrm{d} x \ll l \mathrm{~d} \phi_{m} / \mathrm{d} x
$$

particle potential change between two collisions may be neglected. In aqueous solutions and relatively low bed expansions, condition (1) is mostly fulfilled.

In this case, one particle transfers per second:

$$
I_{p}=\frac{1}{2} v i C_{d}^{0}\left(1-\mathrm{e}^{-t_{d} / \tau}\right) \mathrm{d} \phi_{m} / \mathrm{d} x
$$

By substituting for $l$, the average particle distance, as given by: $2 \epsilon^{1 / 3} r$ and multiplying $I_{p}$ by the number of particles per $\mathbf{m}^{2}$ :

$$
n^{\prime \prime}=1 /\left(2 \epsilon^{1 / 3} r\right)^{2},
$$

Fleischmann et al[3] derived:

$$
\rho_{m}^{-1}=\pi C_{d} v r E^{-1 / 3}\left(1-\mathrm{e}^{-t_{d} / \mathrm{t}}\right)
$$

But due to the 3-dimensional character of particle movement the effective free length in $x$-direction is only half the average particle distance:

$$
l \approx \epsilon^{1 / 3} \gamma
$$

Current density $i$ follows from:

$$
i=I_{p} n l
$$

where $n$ is the number of particles per $\mathrm{m}^{3}$ :

$$
n=3\left(1-\epsilon_{0}\right) /\left(4 \pi r^{3} \epsilon\right)
$$

and $l$ can also be considered as the volume per unit area normal to the $x$ direction that contains the particles which take care of charge transport through that unit arca.

Combination of (2), (4) and (5) results in:

$$
\rho_{m}^{-1}=1.5\left(1-\epsilon_{0}\right) C_{d} u r \epsilon^{-1 / 3}\left(1-\mathrm{e}^{-t_{c /} t}\right)
$$

For $\epsilon_{0}=0.4,(7)$ predicts a conductivity $\rho_{m}^{-1}$ which is ncarly a factor of four lower than obtained with Fleischmann's (3).

The difference is mainly caused by: (1) a factor of two in the assumption of effective $l$ (Equation 4), and (2) a factor of two in (2), due to our assumption that a particle must collide twice to transport one batch of charge over distance $l$.

\section{Parameter values}

Oscilloscopic measurements of $v$ and $t_{c}$ were obtained using an immobile copper particle $\left(r=2.510^{-4} \mathrm{~m}\right)$ connected to an isolated wire in a $f$ be of copper coated glass spheres of same radius. The time interval between two collisions was highly irregular with collisions often occurring in groups. This behaviour suggested 'chain collisions'.

Figure 2 gives time averaged values of the collision frequency as a function of the bed expansion. Because the test particle is not mobile, it may disturb local bed behaviour. Therefore values for collision frequency obtained in this way can only give a rough indication of the real values for completely mobile particles.

If random particle movement on a microscale is assumed, then the measured values are a factor of two too low; but if there is a correlation between the velocities of neighbouring particles the measured values are too high. Nevertheless, it can be concluded from Fig. 2 that for bed expansions up to $\epsilon=1.75$, the collision frequency is in the order of $100 \mathrm{~s}^{-1}$. This value is an order of magnitude lower than the one estimated by Fleischmann et al[3], but is roughly in agreement with measurements of K reysa[4].

We also measured the collision time, $t_{c}$, with the same system for $1.2<\epsilon<1.5$. In this range of bed expansion glass particles with radius of $2.510^{-4} \mathrm{~m}$

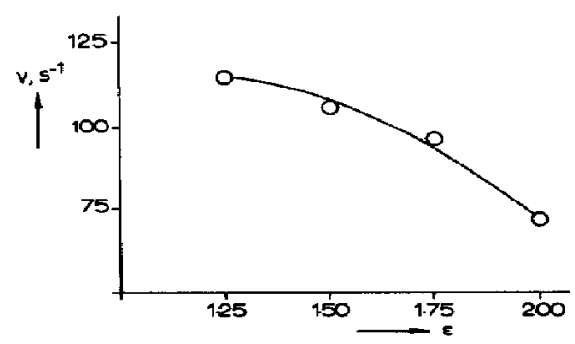

Fig. 2. Collision frequency as a function of bed expansion for copper-coated glass spheres of about $500 \mu \mathrm{m}$ dia. 


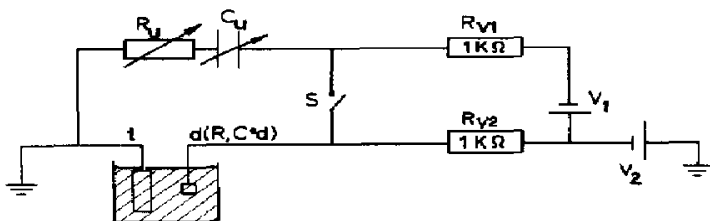

Fig. 3. Experimental set-up for measuring the double layer capacity; $d=$ measuring electrode.

proved to have average contact times which were nearly independent of $\epsilon$ and which were given by:

$$
t_{c}=2.510^{-5} \mathrm{~s}^{-1}
$$

Concerning the $R C$-time constant, $\tau$, the relation used by Fleischmann[3] $\left(\tau=2 r \rho_{s} C_{d}\right)$ predicts an upper value based on the resistance between two particles at infinite distance[5]; but the real value will be lower. From typical values of $r\left(2.5 \times 10^{-4} \mathrm{~m}\right), \rho_{s}$ $\left(5 \times 10^{-2} \Omega \mathrm{m}[1]\right)$ and $C_{d}\left(0.2 \mathrm{~F} / \mathrm{m}^{2}\right.$ (our experiments)) it follows that:

$$
t_{c} / \tau>4
$$

Thus (8) indicates complete charge sharing during collision, and so (7) reduces to:

$$
\rho_{m}^{-1}=1.5\left(1-\epsilon_{0}\right) C_{d} \nu r \epsilon^{-1 / 3}
$$

which indicates a linear relationship between metal phase conductivity and double layer capacity.

We have developed a relatively simple method for measuring $C_{d}$ of a metal surface in electrolyte solution (Fig. 3).

After closing switch $S$, a charge pulse from a variable, known capacity $\left(C_{w}\right)$ flows via a variable, known resistance $\left(R_{u}\right)$ to the unknown double layer capacity $d$ which acts as a capacity resistance element with a typical $R C$-time of the order of $10 \mu$ s. Figure 4 shows the simplified electrical analogue and typical potential-time curves after closing $S$.

For the case that $R_{u} C_{u}=R C_{d}^{0}, C_{d}^{o}$ follows from:

$$
C_{d}^{0}=C_{u} \Delta V_{u} / \Delta V_{d}
$$

Although complications may occur in practice, it has

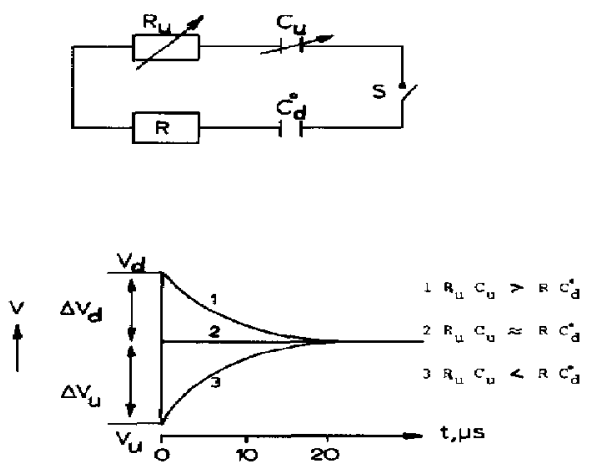

Fig. 4. Simplified electrical analogue of experimental set-up with theoretical change in potential as a function of time of known $\left(\Delta V_{u}\right)$ and unknown capacity $\left(\Delta V_{d}\right)$ after closing switch $S$. Different curves represent different values of the ratio $R_{\mu} C_{w} / R C_{\alpha}^{O}$.

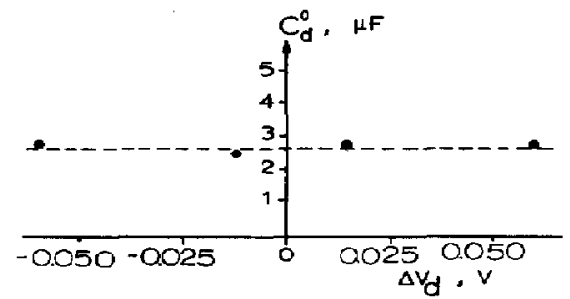

Fig. 5. Double layer capacity as a function of potential change of double layer after closing switch $S\left(\Delta V_{d}\right)$.

been shown that reliable results can be obtained[6]. For copper electrodes in $1 \mathrm{M} \mathrm{H}_{2} \mathrm{SO}_{4}, \mathrm{C}_{d}^{0}$ proved to be independent of the applied $\Delta V_{d}$ (Fig. 5) and of the measuring cell potential $V_{d}-V_{a}$ (Fig. 6). Figure 7 shows results for copper electrodes as a function of concentration in both $\mathrm{KCl}$ and $\mathrm{H}_{2} \mathrm{SO}_{4}$ solutions.

Predicting $\rho_{m}$ from (9) with typical experimental values of $C_{d}\left(0.2 \mathrm{~F} / \mathrm{m}^{2}\right), \quad v\left(100 \mathrm{~s}^{-1}\right)$ and $r$ $\left(2.5 \times 10^{-4} \mathrm{~m}\right)$ gives $\rho_{m} \approx 200 \mathrm{k}^{1 / 3} \Omega \mathrm{m}$, which is roughly a factor 1000 too high compared to the experimental values (Fig. 1). This discrepancy is too high to be explained by a possibly higher $C_{d}$ (which is strongly surface dependent) or by an inaccuracy in measuring $v$ because of the immobile character of the test particle.

So we conclude that a charge transfer model based on ideal particulate fluidization with single particle collisions cannot explain the metal phase conductivity observed experimentally.

\section{CHARGE TRANSFER BASED ON A MODEL OF AGGREGATIVE FLUIDIZATION}

In 1948 Wilhelm et al[7] concluded that liquidsolid fluidization is essentially particulate for systems in which

$$
F r=U_{m j}^{2} / 2 r g<0.2
$$

With the exception of systems with heavy and large particles, all liquid solid systems satisfy this criterion (10)

Contrary to the above, higher Froude numbers are obtained in gas-solid fluidization. In these systems

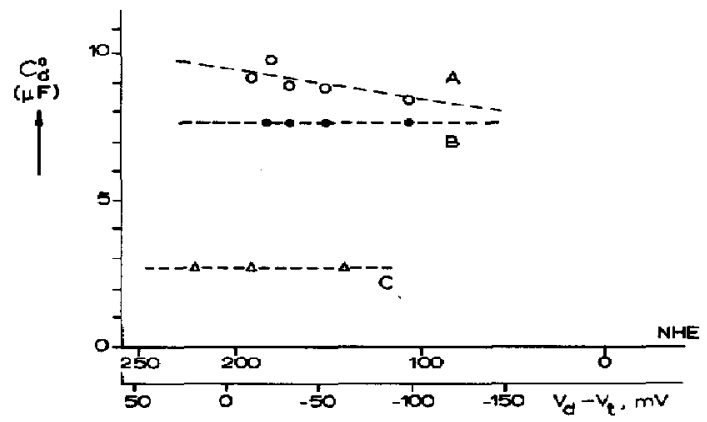

Fig. 6. Double layer capacity $\left(C_{d}^{0}\right)$ as a function of cell potential $\left(V_{d}-V_{t}\right)$ for three different copper electrodes (A, B, C). 
parvoids (gas bubbles) are observed, while the particles keep in electrical contact with each other[7-10]. This type of fluidization is called aggregative. Recently, however, experimental evidence suggests that not only gas-solid, but also liquid-solid fluidization has an aggregative character[11-17]. Possibly, ideal particulate fluidization does not exist $[11,13]$; instead most liquid fluidized beds fall along the transition from the ideal particulate state to fully aggregative fluidization. Apparently, the magnitude of the density difference is the main parameter determining the position along the transition[13]. Even a small density difference of only $290 \mathrm{~kg} / \mathrm{m}^{3}$, however, is suffcicnt to provide a substantial tendency towards aggregative fluidization, as evidenced by the observation of large parvoids and slugs[14]. Therefore we suggested particle aggregates to play a role in the mechanism of charge transfer in the metal phase of a fluidized bed electrode[18]. Additional experimental evidence for this role has recently been reported[19, 20$]$.

Within an aggregate, potential is considered to be uniform. Charge transfer between aggregates is possible by several mechanisms. For an average distance between two adjacent aggregate surfaces $\left(\Delta l_{c}\right)$ smaller than the particle distance, a mechanism of temporary contact bridges appears to be most likely.

Assuming cubic clusters of internal porosity $\epsilon_{0}$, each containing $n_{a}$ particles, the ribbon of a cluster follows from:

$$
a=\left\{n_{a} \frac{4}{3} \pi r^{3} /\left(1-\epsilon_{0}\right)\right\}^{1 / 3}
$$

while the distance between two neighbouring aggregate surfaces is given by:

$$
\Delta l_{a}=a\left(\epsilon^{1 / 3}-1\right)
$$

For $\epsilon_{0}=0.4$, it follows from (12) that $\Delta l_{a}$ is smaller than $2 r$ for $\epsilon<1.4$ and $n_{a}<500$.

In practice the internal porosity of the aggregates will be higher than $\epsilon_{0}$. Equation (12) therefore predicts an upper value for $\Delta l_{a}$.
Analogous to the development of (3), an expression for $\rho_{m}$ can be derived in terms of aggregate parameters:

$$
\rho_{m}^{-1}=\frac{1}{2} v_{a} l_{a}^{2} C_{d a}^{0} N_{a}\left(1-\mathrm{e}^{\cdots t_{a b} / r_{a}}\right)
$$

Because of the mobility of the outer particles, the number of temporary contact bridges between adjacent aggregates per unit time is most likely proportional to the number of particles at the aggregate surface:

$$
v_{a}=b\left(1-\epsilon_{0}\right)^{1 / 3} n_{a}^{2 / 3} v_{a}^{\prime} \quad\left(\text { for } n_{a}>100\right)
$$

with $v_{a}^{\prime}$ the bridge formation frequency of a surface particle. The constant $b$ depends on the aggregate form. For spheric and cubic aggregates $b=6$ and 7.5 . respectively.

After substitution of:

$$
\begin{gathered}
N_{a}=\left(a+\Delta I_{a}\right)^{-3} \\
C_{d a}^{0}=n_{a} 4 \pi r^{2} C_{d} \\
l_{a}=\left(a+\Delta l_{a}\right) / 2
\end{gathered}
$$

and of (14) into (13), the result will be:

$$
\rho_{m}^{-1} \approx 6 n_{a}^{4 / 3} v_{a}^{\prime} C_{d} n \epsilon^{-1 / 3}\left(1-\epsilon_{0}\right)^{2 / 3}\left(1-\mathrm{e}^{-t_{c a} / \tau_{a}}\right)
$$

Although $n_{a}$ and $v_{a}^{\prime}$ are probably functions of both $\epsilon$ and $\left(\rho_{m}-\rho_{s}\right)$, the relationships are unknown at present and not easy to measure. Therefore (15) does not yet give enough information for design purposes. It is clear, however, that aggregative fluidization may result in a lower metal phase resistivity, compared to particulate fluidization. For instance for $\epsilon_{0}=0.4$, $C_{d}=0.2 \mathrm{~F} / \mathrm{m}^{2}, t_{c a} / \tau_{a} \gg 1$ and say $n_{a}=200$ a comparative low value of $v_{a}^{\prime}=10 \mathrm{~s}^{-1}$ (see Fig. 2) is already large enough to predict from (15) the experimentally measured value for $\rho_{m}$ of $0.4 \Omega \mathrm{m}$ for glass spheres of $5 \times 10^{-4} \mathrm{~m}$ dia at $30 \%$ bed expansion $(F i g$. 1).

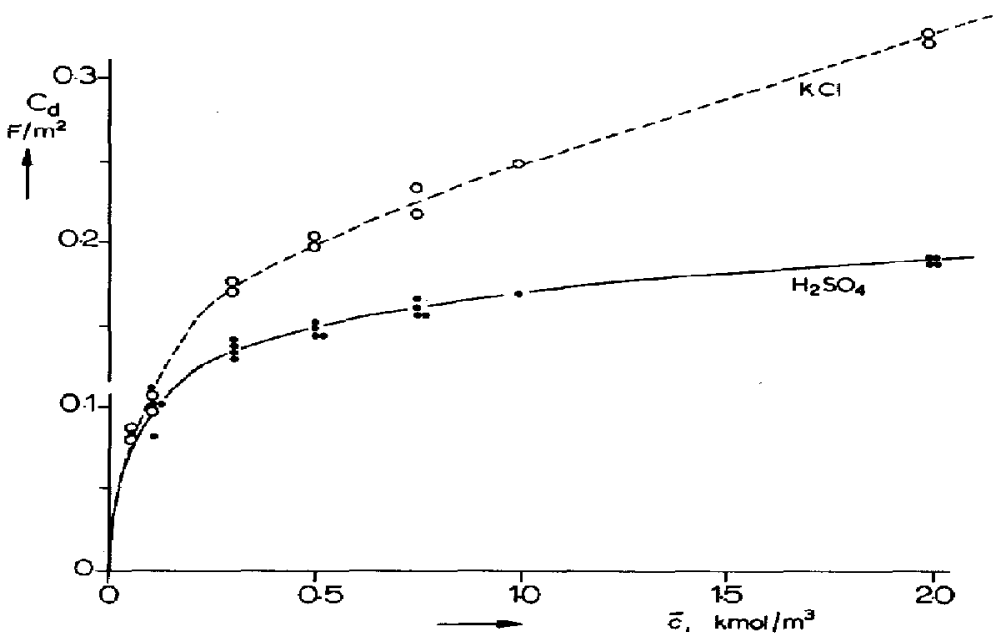

Fig. 7. Double layer capacity of copper $\left(C_{d}\right)$ as a function of electrolyte concentration; $V_{d}-V_{t}=-20 \mathrm{mV}, \Delta V_{d}=30 \mathrm{mV}$ 
Lack of quantitative knowledge of $n_{a}$ and $v_{a}^{\prime}$ demands that further research be conducted on microscale particle behaviour in order to provide a complete description of $\rho_{m}$ from first principles.

\section{REFERENCES}

1. M. Fleischmann, J. W. Oldfield and L. Tennakoon, J. appl. Electrochem. 1, 103 (1971).

2. F. Goodridge, D. I. Holden, H. D. Murray and R. F. Plimley, Trans. Inst. chem. Engrs 49, 137 (1971)

3. M. Fleischmann and J. W. Oldfield, $J$. electroanal. Chem. 29, 231 (1971).

4. G. Kreysa, Personal Communication (1976).

5. J. H. Jeans, The Mathematical Theory of Electricity and Magnetism. Cambridge University Press (1923).

6. A. Welmers, M.Sc: thesis. Twente University of Technology (1974).

7. R. H. Wilhelm and M. Kwauk, Chem. Engng Prog. Symp. Ser. 44, 201 (1948).

8. K. Rielema, in Proceedings of the International Symposium on Fluidisation, (Edited by A. A. H. Drinkenburg) p. 154. Netherlands University Press, Amsterdam (1967).
9. A. L. Jones and T. O. Wheelock, Inst. chem. Engrs Symp. Ser. 30, 174 (1968).

10. P. Goldschmidt and P. Le Goff, Trans. Inst. Chem. Engrs 45, T 196 (1967).

11. N. J. Hassett, Br. chem. Fngng 6, 777 (1961)

12. G. Volpicelli, L. Massimilla and F. A. Zenz, Chem. Engng Prog. Symp. Ser. 62 (67), 42 (1966).

13. A. C. Trupp, Inst. Chem. Engrs Symp. Ser. 30, 182 (1968).

14. V. Vanecek and R. L. Hummel, Inst. Chem. Engrs Symp. Ser. 30, 190 (1968).

15. F. Coeuret, P. Le Goff and F. Vergnes, in Proceedings of the International Symposium on Fluidisation (Edited by A. A. H. Drinkenburg) p. 537. Netherlands University Press, Amsterdam (1967).

16. E. I. Ryan, J. W. Smith and R. L. Hummel, ibid. p. 74

17. A. J. Cairns and J. M. Prausnitz, A.I.Ch.E. Il 6, 554 (1960).

18. W. P. M. van Swaaij, A. A. C. M. Beenackers and A. Welmers, Procesrechniek 31, 458 (1976).

19. D. Handley and D. C. Eardley, Chem. Ind. 330, (1975).

20. F. Coeuret, Electrochim. Acta 21, 203 (1976). 